\title{
Research on Black-Litterman Index Enhancement Strategy_-Based on the Ledoit-Wolf Compression Estimation Method to Optimize the CSI 500 Index Enhancement Strategy
}

\author{
Huixian Zeng ${ }^{1} \&$ Jinguang Zeng $^{1}$ \\ ${ }^{1}$ International Business School of Jinan University 519000, Zhuhai City, Guangdong Province, China \\ Correspondence: Huixian Zeng, Finance Department of International Business School, Jinan University, \\ Qianshan Road 206\#, Zhuhai City, Guangdong Province, Post NO. 519070, China.
}

Received: December 23, 2021

Accepted: January 24, 2022

Online Published: January 26, 2022

doi:10.5539/ibr.v15n2p60

URL: https://doi.org/10.5539/ibr.v15n2p60

\begin{abstract}
Financial risks may often lead to significant losses. A reasonable capital management model can prevent financial risks and enhance financial services to the real economy. The Black-Litterman model can reduce risks through asset allocation. This paper uses the Black-Litterman model to construct an enhanced strategy applied to the CSI 500 Index, and selects the backtest from December 1, 2019 to December 1, 2021. Through the strategy backtest, it can be found that: whether it is considered or not Transaction costs, using analysts' consensus target price as the input point of view of the BL model, can provide excess returns for the index enhancement strategy under relatively stable conditions within the sample interval, and improve the sharpness ratio, information ratio, maximum drawdown, etc. Within the risk-return parameters.

In order to solve the problem of model instability and extreme values of configuration weights in the first step, this paper adjusts the covariance based on the Leodit-wolf compression estimation, thereby optimizing the exponential enhancement model. The backtest results showed that although the volatility and maximum drawdown of the optimized enhanced index model increased slightly, it showed a higher excess return rate and information ratio. Therefore, the BL model optimized based on the compression estimation method can make the model applicable to a wider range, and can be extended to large-scale assets and multi-asset allocation, so that investors have more choices in quantitative investment strategies.
\end{abstract}

Keywords: asset allocation, Leodit-wolf compression estimation method, Black-litterman Index enhancement strategy, quantitative investment

\section{Introduction}

Recently, China's A shares have continued to fluctuate, and the difficulty of investment has increased significantly. At the same time, the CSI 500 Index and other stock indexes that ha not received much attention from investors in the past ushered in a round of long-term structural market. The outstanding excess returns of related stock indexes, the CSI 500 continued strong private equity index enhancement strategy has once again heated up. As of July 2021, the CSI 500 Index has significantly outperformed the Shanghai and Shenzhen 300 Index by more than 14 percentage points, which has attracted the attention of investors. In order to study how to obtain profits through reasonable asset allocation in the structured market, an index enhancement strategy can be considered. The index enhancement strategy using the quantitative method can effectively increase the return on the basis of simple passive investment. Therefore, this paper focuses on the volatility of the CSI 500 to study the strategy of increasing the index.

The difficulties to be overcome for quantitative investment methods from theoretical application to actual application include, but are not limited to, the reverse engineering of some business models and the constant change of parameters according to the market environment. The Black-Litterman model is a semi-open quantitative asset allocation method. The main structure of the model is in Black\&Litterman (1990) has been fully explained, but the setting of its parameters has not yet reached a consensus. But it is also the flexibility of this model setting that gives the BL model the possibility of multiple financial scenarios, and it can be optimized by adding other models and parameter settings. This paper optimizes the BL model by using the Leodit-wolf 
compression estimation method and the improved reference setting method, so that it can be applied to exponential enhancement scenarios and can be promoted.

\section{Literature Review}

The Black-Litterman model is based on the asset allocation theory on the basis of MPT. It uses the Bayesian method to integrate the market equilibrium portfolio with the subjective opinions of investors, and solves the problem of MPT on the basis of implicit market returns and analysts' subjective forecast information. The assumptions in the model are not true, and the parameters are sensitive.Therefore, the choice of balanced combination and subjective opinions plays a crucial role in the choice of model for the final performance of the model. In the BL combined structure for most scholars, such as Black and litterman, Pyo and Lee (2018) et al adopt market combinations as equilibrium combinations. In addition, some scholars will choose to use other methods to construct uniform combinations, such as Haesen (2017) uses the risk parity portfolio as the benchmark equilibrium portfolio of the BL model on the basis of Carhart (2014), etc. Bessler et al. use equal weight combination, minimum variance combination and any combination of assets can be used as the benchmark equilibrium combination of the BL model. Research on subjective opinions is more diversified. Momentum strategies, valuation indicators, low risk premiums, and business cycles are all used to form subjective opinions. However, in the application process of the above BL model, the estimation method of historical covariance matrix is used, and it is often faced with the situation of model instability and extreme values of configuration weights in the process of practice.

The compressed estimation method can optimize the covariance matrix. From the above review, it can be seen that in the use of BL model construction index enhancement strategy, no scholar has used the compressed estimation method to optimize the BL model.This paper draws on Leodit and Wolf to optimize the BL model to overcome problems such as extreme weights based on the covariance compression estimation method. Based on the optimized BL model, based on Zhu(2012), Zhou(2017), Fu(2018) and other scholars' index enhancement quantitative strategy, constructing the CSI 500 index enhancement strategy. In this paper, by constructing the Shrinkage Estimator of the covariance matrix, the problem of the irreversibility of the sample covariance matrix and the excessive estimation error is solved.The outliers in the sample covariance matrix actually bring a lot of estimation errors. Using unprocessed sample covariance matrix for combinatorial optimization will lead to poor weight distribution. The larger the condition number of the covariance matrix, the less stable it is. The condition number of sample empirical variance is generally relatively high, and the covariance of the Ledoit-Wolf compression estimation method can greatly reduce the condition number of the covariance, which is also one of the purposes of most compression methods in practical applications.

Combining the viewpoints of the above-mentioned scholars, it can be seen that in the use of BL model construction index enhancement strategy, no scholar has optimized its stability and weight extreme values. Therefore, the main contributions of this paper are as follows: First, use the compression estimation method to adjust the covariance of the BL model to optimize the CSI 500 index enhancement strategy, which can overcome the instability of the original index enhancement strategy model and extreme weights, etc. Question. Second, by constructing an index enhancement strategy, it is possible to conduct quantitative research on the CSI 500 index with a structural market this year, providing quantitative investors with a richer selection of quantitative strategies. Third, the application of Black- in index investment strategies There are not many empirical studies on the litterman asset allocation model. The strategy simulation of the litterman asset allocation model can further prove the feasibility of the model application.

\section{CSI 500 Index Analysis}

The CSI 500 Index is composed of the top 500 stocks ranked by the total market value after excluding the constituent stocks of the Shanghai and Shenzhen 300 Index and the top 300 stocks in total market value from all A shares. It comprehensively reflects the market value of a group of small and medium-sized stocks in the Chinese A-share market. The company's stock price performance. The CSI 500 Index experienced huge fluctuations from December 1, 2017 to December 1, 2021, with a maximum retracement of 2,200 points and a maximum increase of 3,200 points. Beginning in 2019, the CSI 500 Index has experienced a wave of structural rise, so it has attracted the attention of more institutional investors and individual investors. 


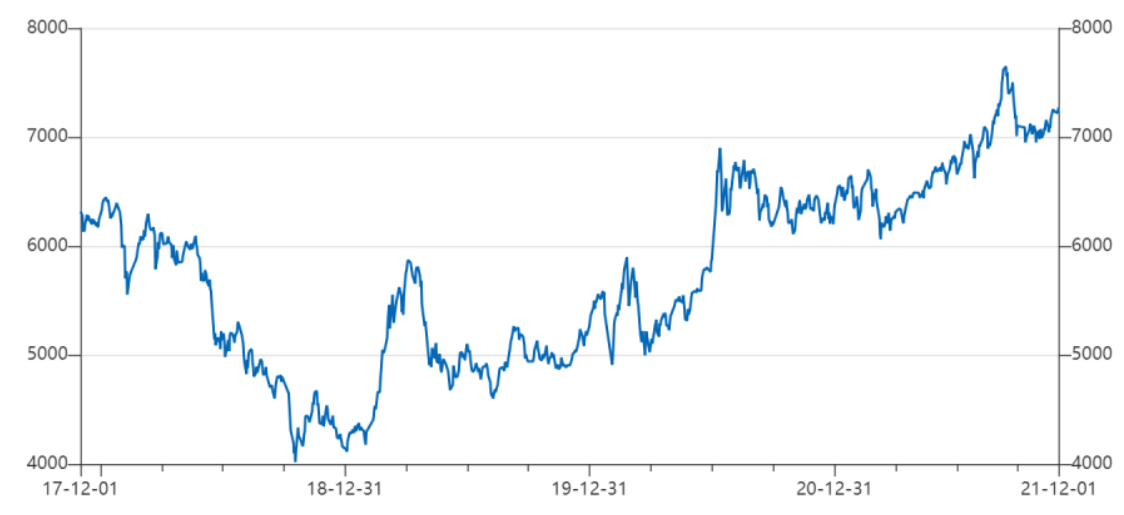

Figure 1. CSI 500 Index Rate Performance

The CSI 500 Index is divided into 10 sectors, namely energy constituents, raw material constituents, industrial constituents, optional constituents, consumer constituents, pharmaceutical constituents, financial and real estate constituents, information constituents, communication constituents and Public constituent stocks. According to Wind's data, there are currently 499 stocks. Therefore, this paper will carry out the weighting ratio based on 10 sectors, and adjust the positions of 499 stocks according to the criteria for judging growth stocks.

For the CSI 500 Index, the current methods for index enhancement mainly include: (1) Refinancing enhancement, that is, strengthening by lending index constituent bonds and charging corresponding fees; (2) IPO enhancement, namely The excess returns obtained by purchasing the latest stocks or convertible bonds when listed; (3) Enhancement using quantitative methods. The first two methods are profitable through efficient capital operations or insufficient market pricing, but their strategic capacity is constant when the market gradually tends to equilibrium.

Shrinking. The quantitative strategy is closer to the nature of index enhancement: by judging the possible excess return opportunities of individual bonds, they are over-allocated in a quantitative way. The BL method provides a model reference for the realization of the quantitative index enhancement strategy, so this paper chooses the CSI 500 index as the index target of the study.

\section{Black-litterman Model CSI 500 Index Enhancement Strategy}

\subsection{Theoretical Basis of the Black-litterman Model}

For BL model parameter estimation, Litterman \& Winkelmann (1996) discussed the estimation method of the covariance matrix, and gave a new covariance matrix estimation method suitable for a large number of asset classes and high-frequency financial time series data, which made up for the lack of big data computing power at that time Shortcomings in computational science. He\&Litterman (2002) believes that the uncertainty of investors' opinions is almost the same as the uncertainty of the overall market, so he sets the opinion error matrix as $\Omega=\operatorname{diag}\left(P^{\prime}(\tau \Sigma) P\right)^{\Omega}$, So now there is only $\tau$ that needs to be determined subjectivel, The value range of the judgment should be within the interval of 0-0.05. Idzorek (2004) proposed a method to quantify parameters $\tau$, which is $\tau=\frac{P^{*} \Sigma P^{* \prime}}{w}$. Moreover, the confidence in the opinion error matrix can be converted into a confidence level by adding the ratio of the posterior allocation and the prior market equilibrium weight after the investor's opinion is added. Based on the quantitative parameter determination method of preset index deviation and excess return certainty, this paper constructs a quantitative passive allocation framework for index enhancement strategies.

\subsection{Construction of Asset Allocation Model Based on Black-litterman}

The BL model follows the standard assumptions of Markowitz's asset allocation theory in terms of investor 
utility, and the representative investor utility function is:

$$
U=w^{\prime} \mu-0.5 \lambda w^{\prime} \Sigma \mu
$$

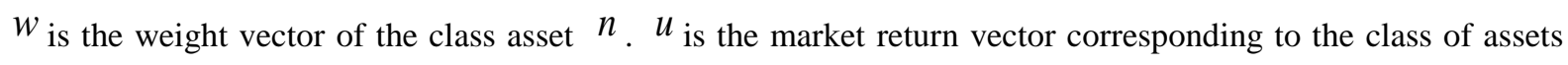
$n . \lambda$ is the investor's risk aversion coefficient. $\Sigma_{\text {is }}$ the covariance matrix of of the returns of the class asset $n$. Both $\lambda$ and $\Sigma$ can be obtained by a variety of different estimation methods.

The BL model's first a priori estimate of the rate of return on assets is not the average of historical data, but is obtained from the equilibrium asset size when the market clears. Assume that the proportion vector of $\mathrm{n}$ types of assets in the current market or in an index is $w_{m k t}$, Formula (1) can be used to reversely find the asset excess return vector at equilibrium $\prod(n \times 1)$ :

$$
\Pi=\lambda \Sigma w_{m k t}
$$

To obtain the posterior expected return vector of the comprehensive equilibrium return and the investor's point of view $E(R)$,The BL model allows investors to make the following three forms of supplementary judgments on assets and form inclusion: View matrix $P(\mathrm{k} \times \mathrm{n})$, Opinion return vector $Q(k \times 1)$ and opinion credibility matrix $\Omega(k \times k)$ of $k(k \leq n)$ investors

According to the Bayesian probability formula, there is:

$$
\operatorname{Pr}(E(R) \mid \Pi)=\frac{\operatorname{Pr}(\Pi \mid E(R)) \times \operatorname{Pr}(\mathrm{E}(\mathrm{R}))}{\operatorname{Pr}(\Pi)}
$$

According to the opinion matrix and the opinion return matrix can be defined $E(R)$, because $P^{*} E(\mathrm{R})=\mathrm{Q}+\varepsilon, \varepsilon$ Is the error of the investor's point of view. If the error of the investor's opinion obeys the standard $\varepsilon \sim N(0, \Omega)$, then there is $P * E(R) \sim N(Q, \Omega)$.

Another scalar is defined to describe investors' trust in a priori excess based on market equilibrium, as follows:

$$
\Pi \mid E(R) \sim N\left(E(R), \tau \sum\right)
$$

The posterior market equilibrium excess return rate can be obtained:

$$
E(R)=\left[(\tau \Sigma)^{-1}+p^{\prime} \Omega^{-1} P\right]^{-1}\left[(\tau \Sigma)^{-1} \Pi+p^{\prime} \Omega^{-1} Q\right]
$$

The corresponding posterior asset allocation weight can be obtained by the inverse calculation of equation (4.2):

$$
w^{*}=(\lambda \Sigma)^{(-1)} E(R)
$$


At this point, we have obtained the BL optimal asset allocation based on various asset information and investor subjective judgments in the comprehensive market equilibrium. However, for index enhancement applications, the economic significance of the parameters needs to be clear and defined.

1.The degree to which the scalar $\tau$ deviates from the exponential configuration. According to formula (4.4), when $\tau \rightarrow 0$, there is $E(R) \rightarrow \prod$. Thus according to formula (4.5), we can get $w^{*} \rightarrow w_{m k t}$. Therefore, the degree ${ }^{\tau}$ to which the $\mathrm{BL}$ enhanced configuration result deviates from the exponential weight can be determined by controlling the size of the scalar.

2.Opinion credibility matrix $\Omega$-Diagonal matrix expression of opinion percentage confidence.It is generally believed that the confidence of an opinion is independent of the relative benefits of the opinion, and the historical correctness of an opinion can be used as an unbiased estimate of its certainty. According to the relevant principles of the Bayesian method, when the degree of confidence in the opinion $\rightarrow 100 \%$, that investors believe the future market rate of return will definitely change according to the direction and magnitude of their judgment, there would be $\Omega \rightarrow 0$.In addition, in general, it can be assumed that the greater the volatility of the return on assets at the point of view, the more difficult and inaccurate the judgment of its future return. So it can use $\frac{1-c_{i}}{c_{i}} P_{i:} \sum P_{i}^{\prime}$

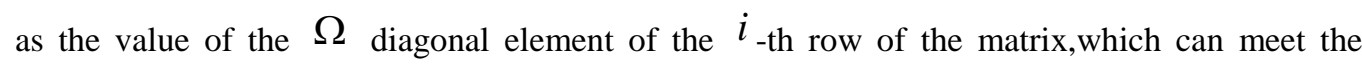
above two characteristics. Where $c_{i}$ is the confidence probability of the investor for the $i_{\text {-th viewpoint, the }}$ value range is 0 to $1 . P$ is the row vector of the ${ }^{i}$-th row of the $P_{\text {matrix. }}$

3. $\lambda$-Risk aversion coefficient matching asset class. The formula for calculating the risk aversion factor of general investors proposed by Idzorek (2004) is $\lambda=E\left(r_{m k t}-r_{f}\right) / \sigma_{m k t}^{2}$ 。Among them, $r_{m k t}$ is the market rate of return, $r_{f}$ is the risk-free rate of return, $\sigma_{m k t}^{2}$ is the variance of the market rate of return. The key lies in what kind of asset is used as the market standard asset and how to determine the risk-free rate of return.

This paper believes that the appropriate market standard asset can be selected as the CSI 500 Index itself, and the risk-free rate of return is the instantaneous yield to maturity of one-year treasury bonds. According to the above modeling steps of the BL model, first, the implicit equilibrium return needs to be required. The risk-free interest rate adopts the one-year treasury bond's instantaneous yield to maturity level of $2.301 \%$. The data needed for inverse optimization are shown in Table 1 to Table 5.

\subsection{CSI 500 Index Strengthening Strategy Construction}

The basic market data selects the daily market data from December 1, 2017 to December 1, 2021, as well as the daily market data of the sample period, total market value data and index weight indicators. The risk-free interest rate level is selected when the exchange is the most liquid Yield to maturity of 1-year Treasury bonds. The 
covariance matrix $\Sigma$ of 499 sample stocks in the China Securities Index can be calculated through market dat. Some indicators need to be set as follows:

1.Consistent target price setting. This paper selects the unanimous target price of the researcher in the Wind terminal as the investor's point of view of individual stock income. Compared with financial data, analysts know that the target price has a higher update frequency, and the calculation of the conversion from the target price to the excess return is relatively clear. The timeliness of the analyst's consensus target price is one month in the future. Assume that the analyst's unanimous target price for the ${ }^{i}$-th stock one month later is $T_{t}$ yuan and the actual price is $A_{t}$ yuan, then the quantitative analyst's historical view confidence is:

$$
c_{i}=\frac{1}{24} \times \sum_{T=t-23}^{t} \frac{\left|A_{t}-T_{t}\right|}{A_{t}}
$$

The rolling time window here is the past 24 months. Therefore, there will be no over-fitting fallacy that uses future data in advance. According to consistent target price data and confidence data, opinion matrix $P$ and opinion credibility matrix $\Omega$ can be formed.

The average return rate of the researcher's unanimous target price from December 1, 2017 to December 1, 2021 can be obtained:

Table 1. Return rate of the researcher's unanimous target price

\begin{tabular}{cccccc}
\hline & $\begin{array}{c}\text { Energy } \\
\text { constituent }\end{array}$ & $\begin{array}{c}\text { Raw material } \\
\text { constituent }\end{array}$ & $\begin{array}{c}\text { Industrial } \\
\text { constituent }\end{array}$ & $\begin{array}{c}\text { Optional } \\
\text { constituent }\end{array}$ & $\begin{array}{c}\text { Consumpti } \\
\text { on } \\
\text { Return } \\
\text { rate }\end{array}$ \\
\cline { 2 - 6 } & $0.05439 \%$ & $0.02350 \%$ & $0.11340 \%$ & $0.01325 \%$ & $0.06364 \%$ \\
Pharmaceutical & Financial Real Estate & Information & Communication & Public \\
constituent & constituent & constituent & constituent \\
rate & $0.05872 \%$ & $-0.05634 \%$ & $0.16678 \%$ & $0.00942 \%$ & $0.00153 \%$ \\
\hline
\end{tabular}

2. Tracking error and no short selling setting. The tracking error range of index-enhanced products on the Chinese market will be agreed to be between 200 and 800 basis points. After many experiments, the tracking error $\tau$ can be controlled within this range. The reasonable value range is 0.0001 to 0.001 .According to $\mathrm{Hu}(2019)$, the backtest result is 0.0005 in the actual backtest. Because the short-selling mechanism in my country's market is not perfect, and index-enhanced products generally do not adopt a long-short strategy, the minimum asset exposure of individual stocks in the backtest investment portfolio is restricted to $0 \%$.

3. Strategy rebalance. The rebalancing frequency of the index enhancement model is set to not once a month, and the strategy sample is updated from the existing investment portfolio to the posterior optimal asset distribution calculated by the BL model. The transaction cost of rebalancing is based on the closing price of the stock at the end of the day, considering the two situations of no transaction cost and fixed ratio transaction cost.

According to the Black-litterman and the above settings, the relevant parameters of the model can be calculated as shown in Table 2 to Table 5: 
Table 2. Covariance matrix of historical estimates of component stock returns

\begin{tabular}{|c|c|c|c|c|c|c|c|c|c|c|}
\hline $\begin{array}{c}\text { Covariance } \\
\text { matrix }\end{array}$ & $\begin{array}{l}\text { Energy } \\
\text { constiment }\end{array}$ & $\begin{array}{l}\text { Raw material } \\
\text { constituent }\end{array}$ & $\begin{array}{l}\text { Industrial } \\
\text { constituent }\end{array}$ & $\begin{array}{l}\text { Optional } \\
\text { constituent }\end{array}$ & $\begin{array}{l}\text { Consunuption } \\
\text { constituent }\end{array}$ & $\begin{array}{c}\text { Phammaceutical } \\
\text { constiment }\end{array}$ & $\begin{array}{c}\text { Financial Real } \\
\text { Estate } \\
\text { constiment }\end{array}$ & $\begin{array}{l}\text { Information } \\
\text { constiment }\end{array}$ & $\begin{array}{l}\text { Conmmunication } \\
\text { constiment }\end{array}$ & $\begin{array}{c}\text { Public } \\
\text { constituent }\end{array}$ \\
\hline $\begin{array}{l}\text { Evergy } \\
\text { constituent }\end{array}$ & 0.0000765 & 0.0000451 & 0.0000334 & 0.0000298 & 0.0000250 & 0.0000233 & 0.0000360 & 0.0000350 & 0.0000311 & 0.0000341 \\
\hline $\begin{array}{l}\text { Raw material } \\
\text { constituent }\end{array}$ & 0.0000451 & 0.0000591 & 0.0000420 & 0.0000338 & 0.0000331 & 0.0000303 & 0.0000361 & 0.0000459 & 0.0000382 & 0.0000298 \\
\hline $\begin{array}{l}\text { Inchstrial } \\
\text { constituent }\end{array}$ & 0.0000334 & 0.0000420 & 0.0000686 & 0.0000354 & 0.0000355 & 0.0000372 & 0.0000329 & 0.0000609 & 0.0000419 & 0.0000264 \\
\hline $\begin{array}{l}\text { Optional } \\
\text { constituent }\end{array}$ & 0.0000298 & 0.0000338 & 0.0000354 & 0.0000447 & 0.0000354 & 0.0000334 & 0.0000313 & 0.0000410 & 0.0000372 & 0.0000221 \\
\hline $\begin{array}{l}\text { Consumption } \\
\text { constituent }\end{array}$ & 0.0000250 & 0.0000331 & 0.0000355 & 0.0000354 & 0.0000608 & 0.0000422 & 0.0000300 & 0.0000412 & 0.0000385 & 0.0000200 \\
\hline $\begin{array}{l}\text { Pharmaceutical } \\
\text { constituent }\end{array}$ & 0.0000233 & 0.0000303 & 0.0000372 & 0.0000334 & 0.0000422 & 0.0000638 & 0.0000274 & 0.0000437 & 0.0000398 & 0.0000200 \\
\hline Financial Real & & & & & & & & & & \\
\hline $\begin{array}{c}\text { Estate } \\
\text { constituent }\end{array}$ & 0.0000360 & 0.0000361 & 0.0000329 & 0.0000313 & 0.0000300 & 0.0000274 & 0.0000499 & 0.0000393 & 0.0000360 & 0.0000282 \\
\hline $\begin{array}{l}\text { Information } \\
\text { constituent }\end{array}$ & 0.0000350 & 0.0000459 & 0.0000609 & 0.0000410 & 0.0000412 & 0.0000437 & 0.0000393 & 0.0000977 & 0.0000565 & 0.0000259 \\
\hline $\begin{array}{l}\text { Conmumication } \\
\text { constituent }\end{array}$ & 0.0000311 & 0.0000382 & 0.0000419 & 0.0000372 & 0.0000385 & 0.0000398 & 0.0000360 & 0.0000565 & 0.0000757 & 0.0000259 \\
\hline $\begin{array}{c}\text { Public } \\
\text { constituent }\end{array}$ & 0.0000341 & 0.0000298 & 0.0000264 & 0.0000221 & 0.0000200 & 0.0000200 & 0.0000282 & 0.0000259 & 0.0000259 & 0.0000429 \\
\hline
\end{tabular}

Table 3. Implied Equillibrium Excess returns

\begin{tabular}{cc}
\hline Constituent & Implied Equillibrium Excess returns \\
\hline Energy constituent & 0.001008191 \\
Raw material constituent & 0.001183269 \\
Industrial constituent & 0.00134098 \\
Optional constituent & 0.00098474 \\
Consumption constituent & 0.001020225 \\
Pharmaceutical constituent & 0.001036145 \\
Financial Real Estate constituent & 0.000990999 \\
Information constituent & 0.001519627 \\
communication constituent & 0.001191917 \\
Public constituent & 0.000754223 \\
\hline
\end{tabular}

Table 4 . Opinion credibility matrix $\Omega$

\begin{tabular}{lllllllll}
\hline 0.0000454 & 0.0000400 & 0.0000354 & 0.0000395 & 0.0000384 & 0.0000315 & 0.0000423 & 0.0000385 & 0.0000271 \\
0.0000004 & 0.0000783 & 0.0000487 & 0.0000536 & 0.0000570 & 0.0000400 & 0.0000690 & 0.0000539 & 0.0000354 \\
0.0000354 & 0.0000487 & 0.0000616 & 0.0000571 & 0.0000568 & 0.0000420 & 0.0000527 & 0.0000528 & 0.0000347 \\
0.0000395 & 0.0000536 & 0.0000571 & 0.0000873 & 0.0000704 & 0.0000455 & 0.0000577 & 0.0000589 & 0.0000374 \\
0.0000384 & 0.0000570 & 0.0000568 & 0.0000704 & 0.0000937 & 0.0000446 & 0.0000619 & 0.0000619 & 0.0000391 \\
0.0000315 & 0.0000400 & 0.0000420 & 0.0000455 & 0.0000446 & 0.0000544 & 0.0000448 & 0.0000454 & 0.0000346 \\
0.0000423 & 0.0000690 & 0.0000527 & 0.0000577 & 0.0000619 & 0.0000448 & 0.0001042 & 0.0000669 & 0.0000333 \\
0.0000385 & 0.0000539 & 0.0000528 & 0.0000589 & 0.0000619 & 0.0000454 & 0.0000669 & 0.0000900 & 0.0000372 \\
0.0000271 & 0.0000354 & 0.0000347 & 0.0000374 & 0.0000391 & 0.0000346 & 0.0000333 & 0.0000372 & 0.0000512 \\
\hline
\end{tabular}


Table 5. BL optimal allocation weight

\begin{tabular}{ccc}
\hline Constituent stocks & $\begin{array}{c}\text { BL optimal configuration } \\
\text { weight }\end{array}$ & $\begin{array}{c}\text { BL optimal allocation weight that does not allow short selling } \\
\left(\mathrm{W}^{*}\right)\end{array}$ \\
\hline Energy constituent & 0.91281 & 0.19821 \\
Raw material constituent & -0.32196 & 0.00000 \\
Industrial constituent & 0.95873 & 0.20818 \\
Optional constituent & -0.50846 & 0.00000 \\
Consumption constituent & 0.84466 & 0.18341 \\
Pharmaceutical constituent & 0.18637 & 0.04047 \\
Financial Real Estate & -1.88472 & 0.00000 \\
constituent & 1.57836 & 0.34273 \\
Information constituent & -0.56392 & 0.00000 \\
Communication constituent & 0.12437 & 0.02701 \\
Public constituent & & \\
\hline
\end{tabular}

According to the above optimal allocation weights, construct the CSI 500 Index enhancement strategy, carry out the fund purchase ratio according to the weights, and set a half-year adjustment of individual stocks in each sector. The basis of the adjustment is based on whether the stock meets the definition of growth stocks Adjust positions, buy or hold if the above indicators are met, and do not buy or sell short if they are not met. The basis for judging growth stocks is shown in Table 6:

Table 6. Standard for judging growth stocks

\begin{tabular}{cc}
\hline Standard serial number & Indicators and standards \\
\hline 1 & Annual net profit growth $\geq 30 \%$ \\
2 & Static P/E Ratio $\leq 30$ \\
4 & ROE $\geq 20 \%$ \\
5 & Assets and liabilities $\leq 70 \%$ \\
\hline
\end{tabular}

Through the above-mentioned model solution and position adjustment strategy setting, the CSI 500 Index enhancement strategy has been established.

\subsection{Strategy Implementation and Backtest Results}

The CSI 500 Index enhancement strategy is implemented through Python using the relevant functions in the Pandas, Windpy and WindAlgo packages. The backtest start time is December 1, 2017, and the end time is December 1, 2021. CSI 500 Total Return Index.

\subsubsection{Backtest Results of BL Index Enhancement Strategy without Considering Transaction Costs}

As shown in Figure 4-1, compared with the basic CSI 500 index, the BL index enhancement model that uses analysts' consistent target price information has a continuous and relatively stable excess return rate, with an annual return rate of approximately $33.05 \%$, and the index The tracking error of the years is $0.50 \%$, indicating that the strategy has a relatively good positive return enhancement. The Beta value of the BL index enhancement model is 0.83 , which shows that compared with the CSI 500 index, this strategy exposes less systemic risks. The smaller maximum backtest of $34.01 \%$ can also illustrate this feature. 


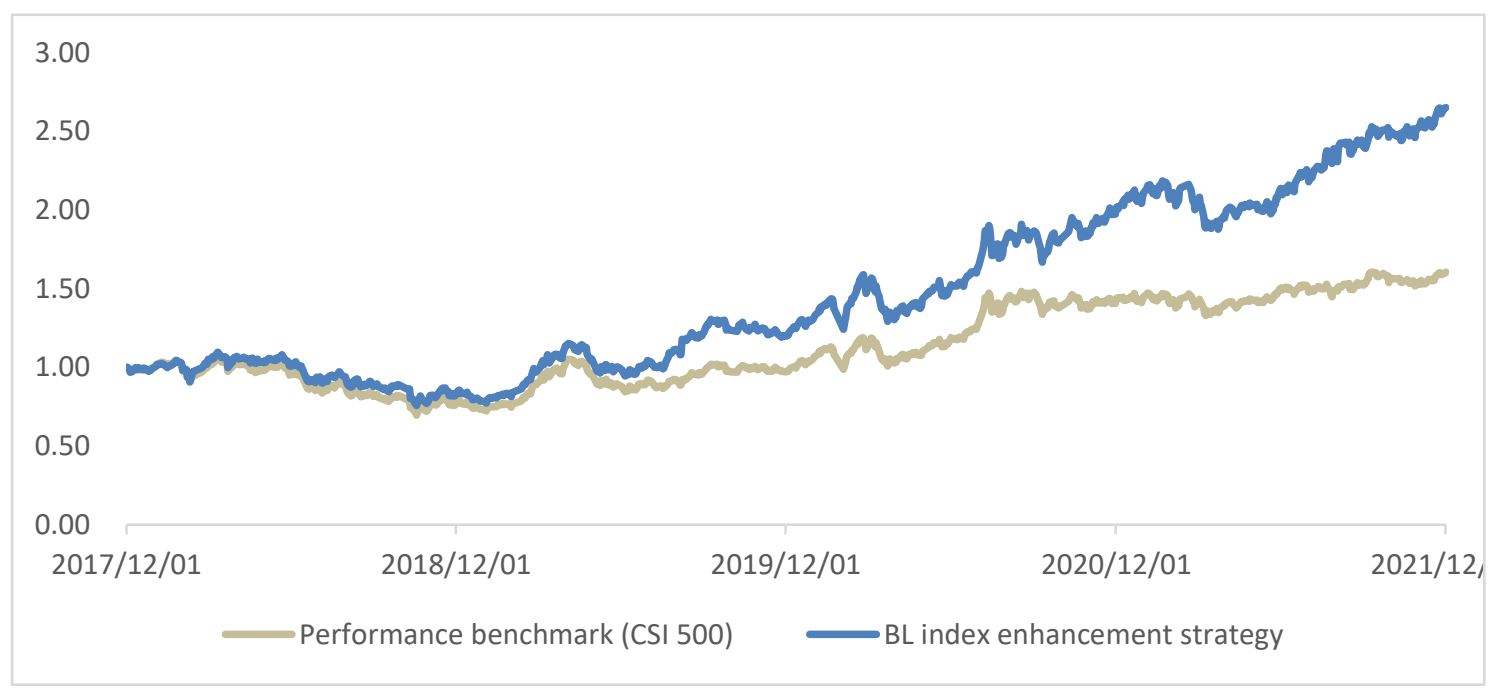

Figure 2. BL index enhancement strategy without considering transaction costs

Table 7. Unoptimized BL index enhancement strategy backtest performance

\begin{tabular}{cccc}
\hline & $\begin{array}{c}\text { BL Index Enhancement } \\
\text { Model Without Considering } \\
\text { Transaction Costs }\end{array}$ & $\begin{array}{c}\text { BL Index Enhancement } \\
\text { Model Considering } \\
\text { Transaction Cost }\end{array}$ & $\begin{array}{c}\text { Performance benchmark } \\
\text { (CSI 500 Index) }\end{array}$ \\
\hline Cumulative rate of return & $265.26 \%$ & $255.62 \%$ & $160.52 \%$ \\
Annualized rate of return & $33.05 \%$ & $32.21 \%$ & $12.10 \%$ \\
Annual tracking error & $0.50 \%$ & $0.50 \%$ & - \\
Maximum drawdown & $34.01 \%$ & $34.17 \%$ & $36.80 \%$ \\
Volatility & $53.74 \%$ & $51.00 \%$ & $26.31 \%$ \\
Sharpe ratio & $0.22 \%$ & $0.22 \%$ & $0.19 \%$ \\
Alpha & $0.03 \%$ & $0.02 \%$ & 0.00 \\
Beta & 0.83 & 0.83 & 1.00 \\
Information ratio & 1.95 & 1.87 & - \\
\hline
\end{tabular}

\subsubsection{Backtest Results of BL Index Enhancement Strategy Considering Transaction Costs}

In the operation of actual index-enhanced products, the transaction cost brought about by repositioning is an expenditure that must be considered, and it will form a drag on product performance in the long run. Based on the BL index enhancement strategy that considering transaction costs, for repositioning transactions, each transaction cost is increased by two thousandths, assuming that repositioning is carried out every six months. The backtest results are shown in Figure 4.2. It can be clearly seen that due to the existence of transaction costs, the benefit advantage of the BL index enhancement strategy relative to the CSI 500 index has been narrowed. 


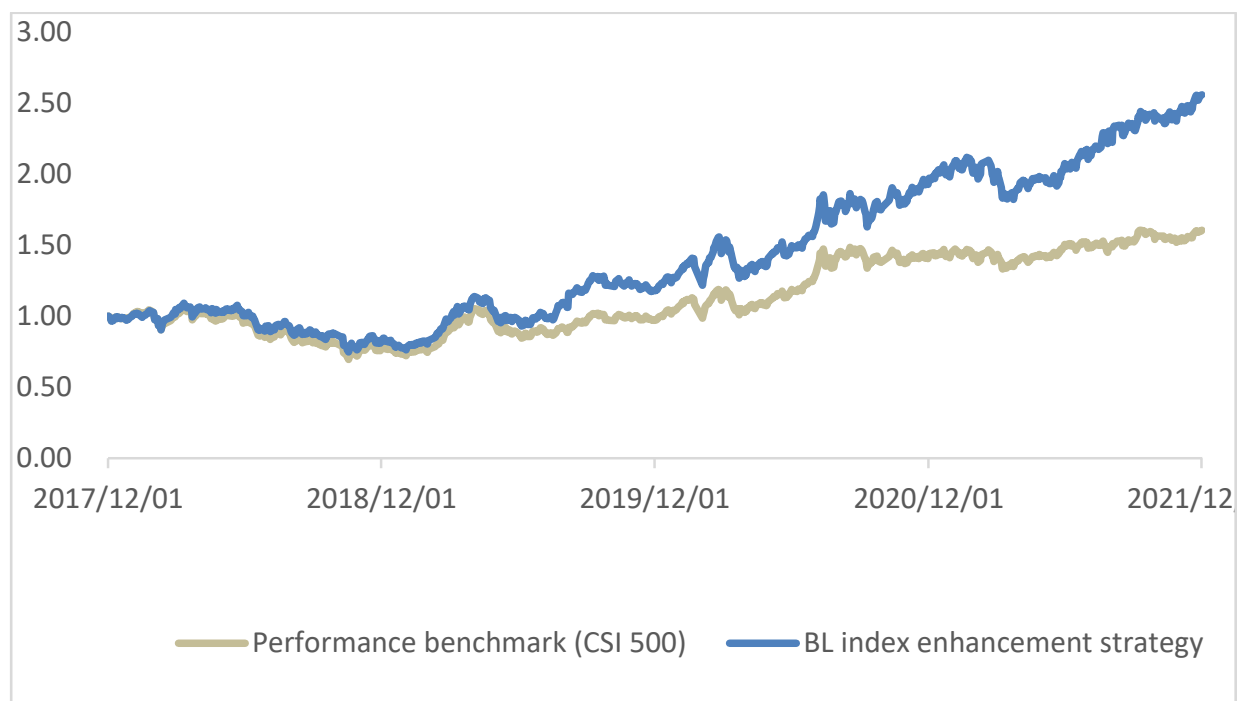

Figure 3. BL Index Enhancement Strategy Considering Transaction Cost

\section{Optimization of Black-litterman Model Based on Leodit-wolf Compression Estimation Method}

\subsection{Solving the Covariance Matrix Based on the Leodit-wolf Compressed Estimation Method}

The usual maximum likelihood estimation of covariance can be regularized using shrinkage methods. Ledoit and Wolf proposed in 2004 to calculate the asymptotically optimal shrinkage parameters by minimizing the MSE criteria, resulting in the Ledoit-Wolf covariance estimation method named after them.

Using the Ledoit-wolf compression method to estimate, a biased estimator that can converge faster and the empirical covariance estimator are combined through the compression coefficient. The new covariance loses a certain degree of unbiasedness but achieves faster convergence. . In fact, as long as it is guaranteed that the estimated amount of superposition is biased, there is generally no limit to its selection. To understand the optimal compression strength from a geometric point of view, the compression estimator is the orthogonal projection of the true covariance matrix on the line connecting the sample covariance and the compression target. In the actual calculation, we can use the identity matrix as the superimposed biased matrix. The new covariance matrix is:

$$
\sum_{\text {shrink }}=\alpha_{1} \phi+\left(1-\alpha_{2}\right) \mathrm{S}
$$

The $\alpha$ compression factor in the formula can be obtained by minimizing the loss between the new covariance and the empirical covariance. $\phi$ is the compression target, and the unit matrix can be used in actual calculations. $S$ is the sample covariance matrix. This method is more suitable when the covariance matrix has more characteristic variables and fewer sample observations.

The key to the compression estimate lies in the determination of the compression strength, which can be estimated through a certain loss function. Ledoit\&Wolf (2003) uses the distance between the covariance compression estimator and the true covariance matrix as the loss function. The distance is measured by the Frobenius norm, that is, the optimal compression strength can be solved by The minimum value of the formula is obtained:

$$
L(\alpha)=\|\alpha \phi+(1-\alpha) S-\Sigma\|^{2}
$$

Under the Forbenius norm loss function. Ledoit and Wolf obtained the asvmntoticallv ontimal linear combination of the identitv matrix and the samnle variance matrix. Thev gave the selection method of $\alpha_{1}$ and $\alpha_{2}$, pointing out that the two are only determined by the following four items: 


$$
\begin{gathered}
\mu=\operatorname{tr}(\Sigma) / \mathrm{p} \\
\alpha=\left\|\Sigma-\mu I_{k}\right\|^{2} \\
\beta=E\|S-\Sigma\|^{2} \\
\delta=E\left\|S-\mu I_{k}\right\|^{2}
\end{gathered}
$$

$p$ is the number of samples, ${ }^{k}$ is the number of parameters, $I_{k}$ is the $k \times k$ unit matrix, and the others are operational variables. A new covariance matrix can be calculated based on the above model.

\subsection{Estimation of Optimization Model Based on Leodit-wolf Compression Estimation Method}

Based on the principle analysis of the above covariance matrix, this part of the software uses Python and loads

\begin{tabular}{|c|c|c|c|c|c|c|c|c|c|c|}
\hline $\begin{array}{c}\text { Covariance } \\
\text { matrix }\end{array}$ & $\begin{array}{l}\text { Energy } \\
\text { constiment }\end{array}$ & $\begin{array}{l}\text { Raw material } \\
\text { constituent }\end{array}$ & $\begin{array}{l}\text { Industrial } \\
\text { constiment }\end{array}$ & $\begin{array}{l}\text { Optional } \\
\text { constiment }\end{array}$ & $\begin{array}{l}\text { Consumption } \\
\text { constituent }\end{array}$ & $\begin{array}{c}\text { Phanmaceutical } \\
\text { constituent }\end{array}$ & $\begin{array}{l}\text { Financial } \\
\text { Real Estate } \\
\text { constituent }\end{array}$ & $\begin{array}{l}\text { Information } \\
\text { constiment }\end{array}$ & $\begin{array}{l}\text { Commumication } \\
\text { constituent }\end{array}$ & $\begin{array}{c}\text { Public } \\
\text { constiment }\end{array}$ \\
\hline $\begin{array}{l}\text { Energy } \\
\text { constituent }\end{array}$ & 0.0000965 & 0.0000451 & 0.0000334 & 0.0000298 & 0.0000250 & 0.0000233 & 0.0000360 & 0.0000350 & 0.0000311 & 0.0000341 \\
\hline $\begin{array}{l}\text { Raw material } \\
\text { constituent }\end{array}$ & 0.0000451 & 0.0000791 & 0.0000420 & 0.0000338 & 0.0000331 & 0.0000303 & 0.0000361 & 0.0000459 & 0.0000382 & 0.0000298 \\
\hline $\begin{array}{l}\text { Industrial } \\
\text { constituent }\end{array}$ & 0.0000334 & 0.0000420 & 0.0000886 & 0.0000354 & 0.0000355 & 0.0000372 & 0.0000329 & 0.0000609 & 0.0000419 & 0.0000264 \\
\hline $\begin{array}{l}\text { Optional } \\
\text { constituent }\end{array}$ & 0.0000298 & 0.0000338 & 0.0000354 & 0.0000647 & 0.0000354 & 0.0000334 & 0.0000313 & 0.0000410 & 0.0000372 & 0.0000221 \\
\hline $\begin{array}{l}\text { Consunption } \\
\text { constituent }\end{array}$ & 0.0000250 & 0.0000331 & 0.0000355 & 0.0000354 & 0.0000808 & 0.0000422 & 0.0000300 & 0.0000412 & 0.0000385 & 0.0000200 \\
\hline $\begin{array}{c}\text { Phanmaceutical } \\
\text { constimuent }\end{array}$ & 0.0000233 & 0.0000303 & 0.0000372 & 0.0000334 & 0.0000422 & 0.0000838 & 0.0000274 & 0.0000437 & 0.0000398 & 0.0000200 \\
\hline $\begin{array}{l}\text { Financial Real } \\
\text { Estate constituent }\end{array}$ & 0.0000360 & 0.0000361 & 0.0000329 & 0.0000313 & 0.0000300 & 0.0000274 & 0.0000699 & 0.0000393 & 0.0000360 & 0.0000282 \\
\hline $\begin{array}{l}\text { Information } \\
\text { constituent }\end{array}$ & 0.0000350 & 0.0000459 & 0.0000609 & 0.0000410 & 0.0000412 & 0.0000437 & 0.0000393 & 0.0001177 & 0.0000565 & 0.0000259 \\
\hline $\begin{array}{l}\text { Conmumication } \\
\text { constituent }\end{array}$ & 0.0000311 & 0.0000382 & 0.0000419 & 0.0000372 & 0.0000385 & 0.0000398 & 0.0000360 & 0.0000565 & 0.0000957 & 0.0000259 \\
\hline Public constituent & 0.0000341 & 0.0000298 & 0.0000264 & 0.0000221 & 0.0000200 & 0.0000200 & 0.0000282 & 0.0000259 & 0.0000259 & 0.0000629 \\
\hline
\end{tabular}
the Ledoit-Wolf package to realize the Ledoit-Wolf compression estimation of the covariance matrix. Table 5.1 shows the covariance calculated by the compressed estimation method:

Table 8. Covariance calculated by Leodit-wolf compression estimation method

Substituting into the Black-litterman model, the final optimal configuration weights that can be calculated and optimized are shown in Table 5.2: 
Table 9. Optimized BL optimal allocation weight

\begin{tabular}{ccc}
\hline Constituent stocks & $\begin{array}{c}\text { BL optimal configuration } \\
\text { weight }\end{array}$ & $\begin{array}{c}\text { BL optimal allocation weight that does not allow short } \\
\text { selling }\left(\mathrm{W}^{*}\right)\end{array}$ \\
\hline Energy constituent stocks & 0.43819 & 0.15207 \\
Raw material constituent stocks & -0.00783 & 0.00000 \\
Industrial constituent stocks & 0.79216 & 0.27492 \\
Optional constituent stocks & -0.23493 & 0.00000 \\
Consumption constituent stocks & 0.38905 & 0.13502 \\
Pharmaceutical constituent & 0.20180 & 0.07004 \\
stocks & -0.90545 & 0.00000 \\
Financial Real Estate constituent & 1.06024 & 0.36795 \\
stocks & -0.32117 & 0.00000 \\
Information constituent stocks & -0.08582 & 0.00000 \\
Communication constituent & & \\
stocks & & \\
Public constituent stocks & &
\end{tabular}

\subsection{Implementation of Optimized CSI 500 Index Enhancement Strategy and Backtest Results}

According to the optimized CSI 500 index enhancement strategy model, as in the previous section, it is implemented through Python using the relevant functions in the Pandas, Windpy and WindAlgo packages. The backtest start time is December 1, 2017, and the end time is December 1, 2021.

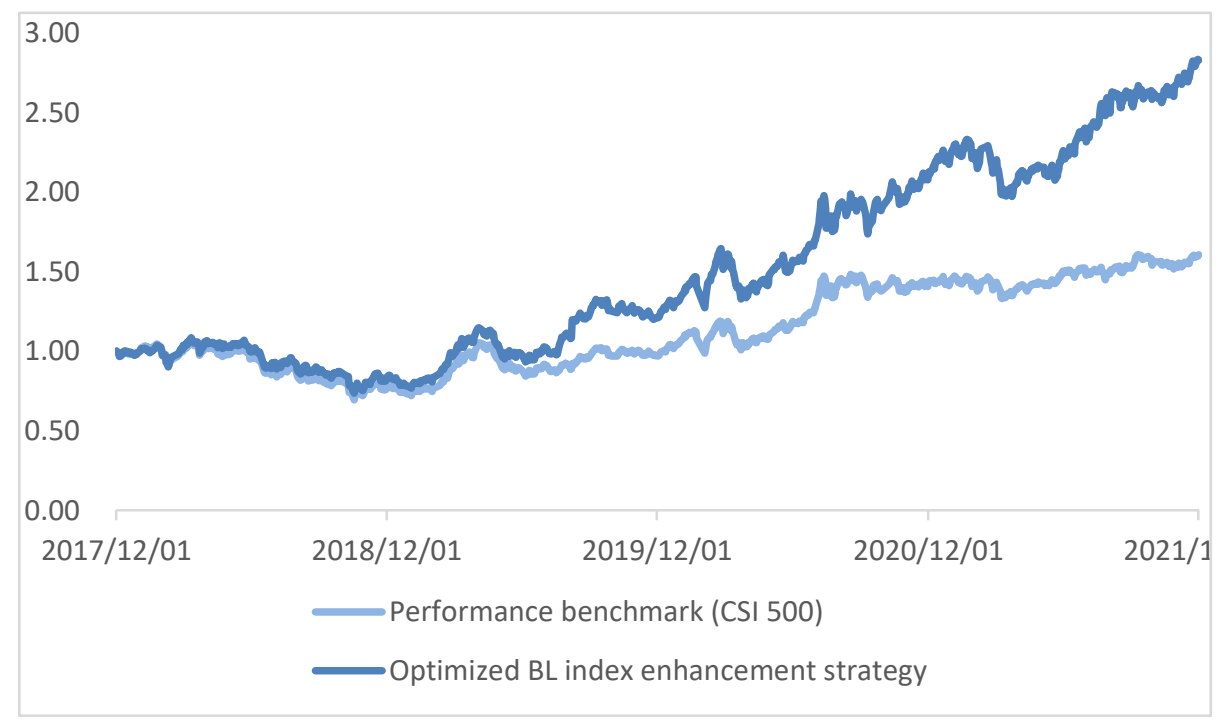

Figure 4. Optimized BL index enhancement strategy without considering transaction costs

\subsubsection{Backtest Results of Optimized BL Index Enhancement Strategy without Considering Transaction Costs}

As shown in Figure 5.1 and Table 5.3, compared to the unoptimized BL index enhancement strategy that does not consider transaction costs and the basic CSI 500 index, the optimized BL index enhancement model has a higher excess return rate, and the annualized return rate is about It is $36.60 \%$, which is $1.43 \%$ higher than before optimization. The information ratio has been increased from 1.97 to 2.05. The Beta value is 0.79 . Compared with the CSI 500 Index, this strategy also exposes fewer system risks.

However, the maximum retracement of the strategy has increased from $35.04 \%$ to $35.72 \%$, and the volatility has increased from $57.88 \%$ to $59.81 \%$, indicating that the risk of the optimized strategy has slightly increased. 
Table 10. Summary of BL index enhancement strategy backtest performance

\begin{tabular}{cccccc}
\hline & $\begin{array}{c}\text { Optimized BL } \\
\text { Index } \\
\text { Enhancement } \\
\text { Model Without } \\
\text { Considering } \\
\text { Transaction Costs }\end{array}$ & $\begin{array}{c}\text { Optimized BL } \\
\text { Index } \\
\text { Enhancement } \\
\text { Model } \\
\text { Considering } \\
\text { Transaction Cost }\end{array}$ & $\begin{array}{c}\text { BL Index } \\
\text { Enhancement } \\
\text { Model Without } \\
\text { Considering } \\
\text { Transaction Costs }\end{array}$ & $\begin{array}{c}\text { BL Index } \\
\text { Enhancement } \\
\text { Model } \\
\text { Considering } \\
\text { Transaction Cost }\end{array}$ & $\begin{array}{c}\text { Performance } \\
\text { benchmark (CSI } \\
500 \text { Index) }\end{array}$ \\
\hline $\begin{array}{c}\text { Cumulative rate } \\
\text { of return }\end{array}$ & $282.99 \%$ & $275.87 \%$ & $265.26 \%$ & $255.62 \%$ & $160.52 \%$ \\
$\begin{array}{c}\text { Annualized rate } \\
\text { of return }\end{array}$ & $36.60 \%$ & $35.17 \%$ & $33.05 \%$ & $32.21 \%$ & $12.10 \%$ \\
$\begin{array}{c}\text { Annual tracking } \\
\text { error }\end{array}$ & $0.59 \%$ & $0.59 \%$ & $0.50 \%$ & $0.50 \%$ & - \\
$\begin{array}{c}\text { Maximum } \\
\text { drawdown }\end{array}$ & $35.72 \%$ & $35.04 \%$ & $34.01 \%$ & $34.17 \%$ & $36.80 \%$ \\
$\quad \begin{array}{l}\text { Volatility } \\
\text { Sharpe ratio }\end{array}$ & $59.81 \%$ & $57.88 \%$ & $53.74 \%$ & $51.00 \%$ & $26.31 \%$ \\
$\quad \begin{array}{c}\text { Alpha } \\
\text { Beta }\end{array}$ & $0.21 \%$ & $0.21 \%$ & $0.22 \%$ & $0.22 \%$ & $0.19 \%$ \\
Information ratio & $0.03 \%$ & $0.03 \%$ & $0.03 \%$ & $0.02 \%$ & 0.0000 \\
\hline
\end{tabular}

\subsubsection{Backtest Results of Optimized BL Index Enhancement Strategy Considering Transaction Costs}

Based on the optimized BL index enhancement strategy considering transaction costs, for repositioning transactions, each transaction cost is increased by two thousandths, assuming that repositioning is carried out every six months. The backtest results are shown in Figure 5.2. It can be clearly seen that due to the existence of transaction costs, the benefit advantage of the BL index enhancement strategy over the CSI 500 index has also been narrowed.

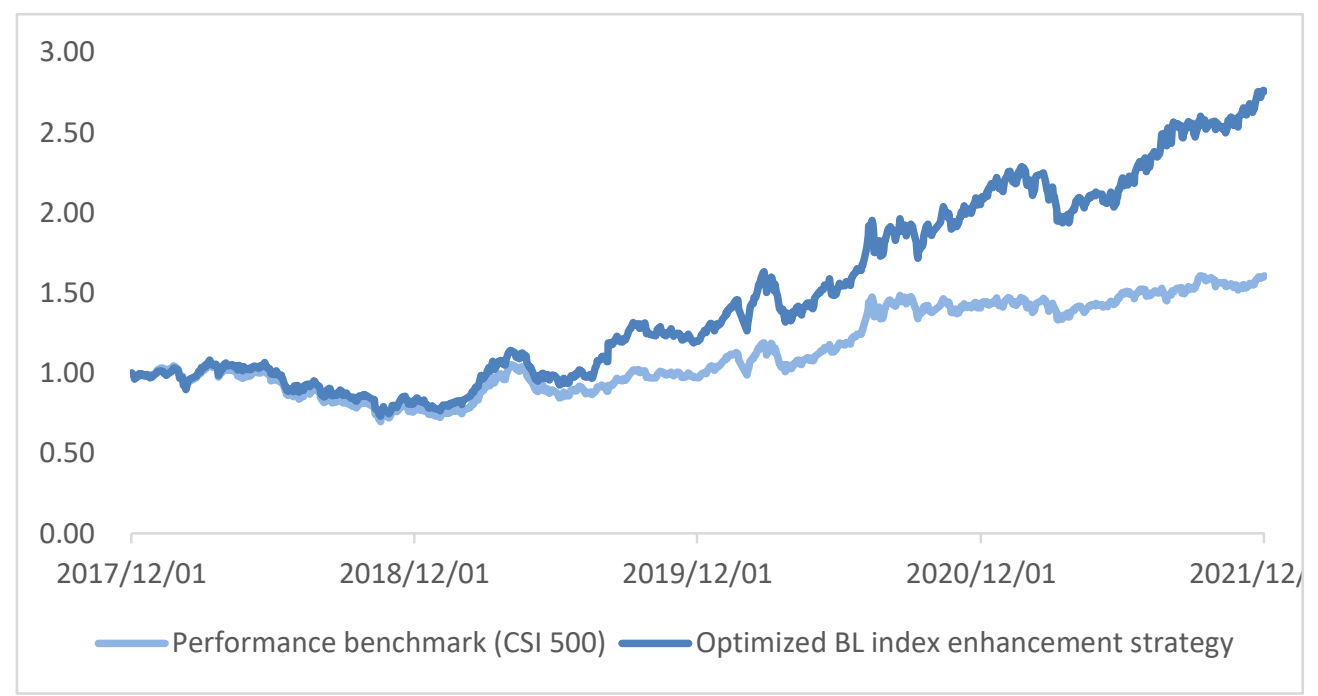

Figure 5. Optimized BL index enhancement strategyconsidering transaction costs

\section{Conclusion}

This paper uses the relevant data of the CSI 500 Index from December 1, 2017 to December 1, 2021, and innovatively uses the Ledoit-Wolf compression estimation method to optimize the Black-Litterman model to construct the CSI 500 index enhancement strategy. According to the strategy backtest results of the BL CSI 500 Index enhancement strategy, the results are as follows:

The index enhancement strategy optimized with the Ledoit-Wolf compression estimation method has a higher excess return rate and information ratio, that is, it can be better than the performance of the performance benchmark CSI 500 Index. But at the same time there is a higher volatility and a maximum retracement, so the optimized strategy corresponds to a higher risk. (2) On the whole, the Black-litterman-based CSI 500 index enhancement strategy before and after optimization can achieve excess returns compared with the CSI 500 index, and has a higher Sharpe ratio, information ratio and smaller Maximum drawdown. Therefore, the index 
enhancement strategy performs well, which can bring excess returns to investors within the sample range and reduce risks to a certain extent. (3) It can be seen from the results that using the researcher's consistent target price as the rate of return input condition can effectively improve the risk-return parameters of the asset portfolio, so that the index enhancement strategy constructed by the Black-Litterman model has better performance than the benchmark. The BL model can perform well. Adapt to the index enhancement scenario.

The CSI 500 index enhancement strategy based on the Ledoit-Wolf compression estimation method to optimize the Black-Litterman quantitative model performed well in the backtest, so the author makes the following suggestions:

1. It is reasonable to add other valid viewpoints to the Black-litterman model. With the development of my country's financial market, there will be more and more quantitative investment based on indexes. Therefore, the Black-litterman model can be used reasonably to obtain excess returns. The viewpoint matrix in this paper adopts the consistent target price of Wind researchers. In actual application, in addition to the researcher's consistent target price as the input condition of the rate of return, it can also be input into the model based on subjective but not quantifiable information such as public opinion information. To deal with the impact of macroeconomic and stock market fundamental changes on the strategy.

2. When constructing a quantitative model, suitable optimization methods should be found according to the possible defects of the model. For example, the covariance of the Black-litterman model used the historical covariance matrix estimation method in previous researches. In practice, the model is prone to instability and extreme values of configuration weights are often encountered, but no measures have been taken. Optimize it. The use of optimization based on the Ledoit-Wolf compression estimation method can broaden the application scenarios of the Black-litterman model. Therefore, when building a quantitative model and setting parameters, the model must be adjusted through sufficient mathematical operations and empirical backtesting, and effective and rapid model adjustments must be made in accordance with changes in the market and changes in the underlying assets of the application.

3. Quantitative investment strategies should consider strategies with high scalability. Priority is given to building a highly versatile asset allocation framework model. The BL model has a good effect on the enhanced allocation of a single asset with a representative index, such as stocks, bonds, commodities, etc. A highly versatile asset allocation framework can make the strategic logic of quantitative investment institutions more malleable, the depth of optimization will be higher, and the strategy development will have more synergistic effects.

\section{References}

Bessler, W., Opfer, H., \& Wolff, D. (2017). Multi-asset portfolio optimization and out-of-sample performance: an evaluation of black-litterman, mean-variance and nave diversification approaches [J]. European Journal of Finance, 2017(1), 1-30. https://doi.org/10.1080/1351847X.2014.953699

BlackF, L. R. (1990). Asset Allocation: Combining Investors Views with Market Equilibrium[J]. Fixed Income Research, 1990(9).

Carhart, M., Cheah, U. W., DeSantis, G., Farrell, H., \& Litterman, R. (2014). Exotic beta revisted [J]. Financial Analysts Journal, 2014(5), 24-52. https://doi.org/10.2469/faj.v70.n5.4

Fu, Z. J., \& Wu, Q. Q. (2018). Research on Quantitative Timing of Market Index Based on Hidden Markov Model[J]. Journal of Xiamen University (Natural Science Edition), 57(03), 404-412.

Haesen, D., Hallerbach, W. G., Markwat, T., \& Molenaar, R. (2017). Enhancing risk parity by including views[J]. Journal of Investing, 2017(4), 53-68. https://doi.org/10.3905/joi.2017.26.4.053

Hu, G. Y., \& Fan, M. T. (2019). Research on the Application of Asset Allocation Quantity Method under the New Asset Management Regulations_- The SSE 50 Index Enhancement Strategy Based on the Improved Black-Litterman Model[J]. Price Theory and Practice, 2019(11), 101-104+168.

Idzorek, T. M., \& Bertsch, F. (2004). The Style Drift Score[J]. The Journal of Portfolio Management, 31(1). https://doi.org/10.3905/jpm.2004.443323

Oliver, L., \& Michael, W. (2004). Improved estimation of the covariance of the covariance of the covariance matrix of stock returns with an application to portfolio seleciton. Journal of Emprical Finance, 10, 603-621. https://doi.org/10.1016/S0927-5398(03)00007-0

Pyo, L. J. (2018). Exploiting the low-risk anomaly using machine learning to enhance the Black-Litterman framework: Evidence from South Korea[J]. PACIFIC-BASIN Finance Journal, 2018(51), 1-12. https://doi.org/10.1016/j.pacfin.2018.06.002 
Wang, H. (2021). CSI 500 continued strong private equity index enhancement strategy is heating up again [N]. China Securities Journal.

Zhou, L. (2017). Research on index tracking and enhancement strategies based on cointegration[J]. Economic Mathematics, 34(03), 77-83.

Zhu, Z. (2012). Research on Index Fund Enhancement Strategy Innovation[J]. Finance and Accounting Monthly, $36,46-48$.

\section{Copyrights}

Copyright for this article is retained by the author(s), with first publication rights granted to the journal.

This is an open-access article distributed under the terms and conditions of the Creative Commons Attribution license (http://creativecommons.org/licenses/by/4.0/). 